\title{
A Educação ambiental e a valorização do património natural de São Tomé e Príncipe: contributos e desafios para o desenvolvimento local
} Environmental education and the valuation of
São Tomé and Príncipe's natural heritage:
contributions and challenges for local development

Mário Acácio B. M. C. Oliveira e Olga Maria A. P Santos. INE-Instituto Politécnico de Leiria (Portugal).

\begin{abstract}
Resumo
O património natural de São Tomé e Príncipe tem vindo a ser identificado e reconhecido pela comunidade científica, processo em que se tem destacado mais a sua riquíssima diversidade biológica que a geológica, não obstante a sua relativa importância. 0 relacionamento da comunidade com os recursos naturais do arquipélago tem vindo a intensificar-se e a promover impactos significativos, como o atestam a progressiva depleção da floresta, a erosão costeira e a extração furtiva de inertes, entre outras situações identificadas. Promover um maior e melhor conhecimento do património natural de São Tomé e Príncipe, bem como de modelos de relacionamento mais harmoniosos entre a comunidade e este património, é um desígnio da Educação Ambiental. A Educação Ambiental torna-se promotora da sensibilização, formação, divulgação, promoção $e$ valorização do conhecimento relativo ao património natural/ambiental, tornando-se um veículo de intervenção e desenvolvimento comunitário. Pode contribuir, assim, para o desenvolvimento do arquipélago aos seus vários níveis -abarcando múltiplos atores nesse processo educativo, nomeadamente estabelecimentos de ensino, organizações não-governamentais com preocupações ambientais e de desenvolvimento, ordens profissionais e poder político, entre outros- exigindo também o estabelecimento de uma rede de cooperação/parcerias essencial ao país e à defesa do seu património natural.
\end{abstract}

\section{Astract}

The natural heritage of São Tomé and Príncipe archipelago has been identified and recognized by the scientific community, a process in which its rich biological diversity has been more prominent than geological diversity, despite its relative importance. The community's relationship with the natural resources of the archipelago has been intensifying and promoting significant impacts, as evidenced by the progressive depletion of the forest, coastal erosion and furtive extraction of aggregates, among other identified situations. To promote a greater and better knowledge of the natural heritage of São Tomé and Príncipe, as well as more harmonious relationship models between the community and this heritage, is a design of Environmental Education. Environmental Education becomes a promoter of the awareness, formation, dissemination, promotion and valorization of knowledge related to the natural / environmental heritage, becoming 


\begin{abstract}
a vehicle for intervention and community development. It may contributes to the development of the archipelago at its various levels - encompassing multiple actors in this educational process, including educational establishments, non-governmental organizations with environmental and development concerns, professional orders and political power, among others - of a network of cooperation / partnerships essential to the country and the defense of its natural heritage.

Palavras chave

Educação Ambiental; Património natural; Biodiversidade; Geodiversidade; Rede de Geossítios de São Tomé e Príncipe.

\section{Key-words}

Environmental Education; Natural Heritage; Biodiversity; Geodiversity; São Tomé e Príncipe Geosites Network.
\end{abstract}

\section{Introdução}

\section{A República Democrática de São Tomé e Príncipe é um arquipélago localizado no} Golfo da Guiné, a aproximadamente trezentos quilómetros da costa ocidental africana e sobre o equador, linha imaginária que atravessa o Ilhéu das Rolas. O conjunto de ilhas que constitui este arquipélago possui origem vulcânica, inserindo-se, segundo MunHÁ, et al. (2007, p.5), no "troço oceânico do alinhamento vulcânico dos Camarões, que se estende por 1600 quilómetros, desde o interior do continente africano a NE (...) até à ilha de Pagulu (Ano-Bom) a SW (...)".

Este arquipélago é constituído por duas ilhas de maiores dimensões -a ilha de S. Tomé, com aproximadamente 857 km2, e a ilha do Príncipe, com cerca de 142 Km2, as quais cederam o nome pelo qual o país é internacionalmente comummente designado (São Tomé e Príncipe)- e por um vasto conjunto de pequenos ilhéus, de que se destacam os bem conhecidos Ilhéu das Cabras, Ilhéu das Rolas, Ilhéu Bom Bom, Ilhéu Boné de Jóquei, para além do llhéu de Santana, o llhéu Catarino, o Ilhéu Quixibá, o Ilhéu Sete Pedras, o Ilhéu Jalé e o Ilhéu dos Côcos, Ilhéu Tinhosa Grande, Ilhéu Tinhosa Pequena, entre muitos outros.

A ilha de S. Tomé possui no Pico de S. Tomé o seu relevo de cota mais elevada, com 2024 metros de altitude, ainda que possua algumas outras elevações com cotas superiores a 1000 metros, essencialmente localizadas na sua parte sul. Este relevo condiciona as bacias hidrográficas desta ilha, as quais são constituídas por uma rede de ribeiras correm das zonas montanhosas, em vales relativamente encaixados, onde, por vezes, se precipitam em cascatas, como a cascata de S. Nicolau, muitas delas com potencial interesse geológico, turístico e pedagógico; estas ribeiras acabam por gerar rios cuja foz apresenta, frequentemente, sedimentos de grandes dimensões, bastante rolados, em resultado dos regimes torrenciais verificados. 
A ilha do Príncipe possui um relevo bastante menos acentuado do que a ilha de São Tomé, conforme se pode constatar se referirmos que o Pico do Príncipe, o maior relevo da ilha, apenas alcança os 848 metros de altitude. A exemplo do que sucede com o relevo, também a hidrografia da ilha do Príncipe se revela bastante menos exuberante, sobressaindo o rio Papagaio e um conjunto de ribeiras com origem na região montanhosa central (CARDOSo \& GARCIA, 1962). Também nesta ilha é possível encontrar algumas cascatas, relevantes em termos paisagísticos e de exploração turística, mas também na perspetiva geológica e pedagógica, como sucede, por exemplo, com a cascata Ôque Pipi, entre outras.

O arquipélago tem origem vulcânica, facto facilmente identificável na paisagem das ilhas e ilhéus que o constituem, bastando atentar na existência de elevado número de crateras de vulcões inativos, das quais, porventura a mais famosa seja a mui conhecida Lagoa Amélia, na ilha de S. Tomé, ou, ainda, na ocorrência de bastantes estruturas geológicas associadas a episódios de vulcanismo, de afloramentos rochosos e, mais raramente, de manifestações secundárias de vulcanismo.

Será, justamente, à geomorfologia destas ilhas e ilhéus, bem como à sua localização geográfica e condições climáticas particulares daí resultantes, que se ficará a dever a relevante diversidade biológica existente no país, bem como da sua estratificação e distribuição pelos distintos ecossistemas conhecidos. Saliente-se, neste particular, o elevado número de endemismos identificados, facto a que não será alheio, justamente, a situação em que o isolamento geográfico decorrente do facto de se tratar de ilhas e ilhéus, nalguns casos bastante distantes entre eles.

Para além da biodiversidade associada ao meio terrestre, também o estudo do mundo subaquático associado a estas ilhas e ilhéus tem permitido conhecer uma notável diversidade biológica, com natural destaque para a importância da ocorrência de mais de duas dezenas de espécies de cetáceos e das 4 espécies de tartaruga que desovam regularmente nas praias do arquipélago, conforme referem REEVES, Stewart, Clapham \& Powel, mencionados por GonÇALVES (2010).

A relevância da riqueza biológica do arquipélago encontra-se reconhecida internacionalmente através de um cada vez mais vasto conjunto de publicações científicas (Leventis \& Olmos, 2009; Mendes \&Sousa, 2012; LIMA, 2012), onde se pode aferir o elevado número de espécies endémicas o que confere as ilhas um estatuto de prioridade no tocante a estratégias de conservação, mas, também, de reconhecimento pela UNESCO, em 2012, da Ilha do Príncipe como Reserva Mundial da Biosfera. Naturalmente, essa importância traduz-se, também, numa maior preocupação com a 
sua recuperação, conservação e gestão, domínios em que a educação ambiental começou já a desempenhar um papel relevante e, naturalmente, a produzir alguma documentação de suporte a atividades de formação e sensibilização em matéria de ambiente, em contextos educativos formais e informais (MARAPA, 2009; OLIVEIRA \& SANTOS, 2013; PINTO \& LIMA, 2014).

Considerando, como referem Brilha, et al. (MAgAlhães, 2013, pg. 169), referindo Gray (2004), que «a geodiversidade diz respeito à variedade natural de minerais, rochas, fósseis e geoformas, sendo o seu valor diversificado, contemplando fatores intrínsecos, culturais, ecológicos, estéticos, económicos funcionais, científicos e educativos», somos levados a reconhecer que a geodiversidade do país não se revela tão exuberante quanto a biodiversidade. Todavia, apesar da sua menor relevância, o contributo do patrimonio geológico para o património natural global de São Tomé e Príncipe merece ser evidenciado e, naturalmente, recuperado, valorizado e dignificado. Com efeito, estabelecendo um paralelo sobre a importância atribuída ao patrimonio geológico do país, analisado-o comparativamente ao biológico, rapidamente se percebe que continua a ser mal conhecido e, de forma geral, maioritariamente valorizado apenas enquanto recurso mineral e, por isso, explorável, com impactes impossíveis de remediar, na maior parte das situações.
Dessa forma, é possível, em vários locais do arquipélago, encontrar atividades humanas, com destaque para as explorações mineiras, cujos impactes podem estar a colocar a geodiversidade/patrimonio geológico em risco, comprometendo, eventualmente, potenciais futuras utilizações nas vertentes (eco)turística e pedagógica, por exemplo, e, por essa via, o desenvolvimento das comunidades locais e o rendimento económico do próprio país.

A título de exemplo, atente-se no risco de perda definitiva que corre a magnífica frente de exploração da Pedreira de Palmar, quase integralmente constituída por basalto, cuja disjunção prismática, ou colunar, se apresenta particularmente bela e bem conservada. Naturalmente, esta exploração, embora legítima, poderia vir a dar lugar a um proceso negocial de transferência da unidade de exploração para outro local, salvaguardando aquela estrutura geológica para efeito pedagógicos e/ou turísticos, integrando-a uma rede de geossítios a constituir a nível nacional. Esta rede, debidamente equacionada em função de exigentes e critérios de seleção, poderia englobar uma vasto conjunto de geossítios -como, por exemplo, a Pedreira de Palmar (Fotografias 1 e 2), as nascentes de águas gaso-carbónicas de Queluz, Madre de Deus, Boa Entrada, Caixão Grande e Palha, os Picos do Príncipe e do Cão Grande (Fotografia 3), as cascatas de S. Nicolau e Ôque Pipi (Fotografias 4 e 5), estruturas filoneanas varias (Fotografia 6), 

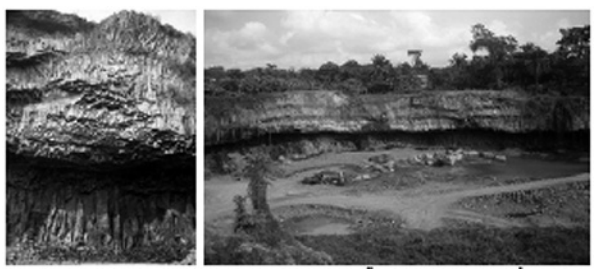

Fotografia 1: Pedreira de Palmar

Fotografia 2: Disjunção colunar, ou prismática, do basalto na Pedreira de Palmar

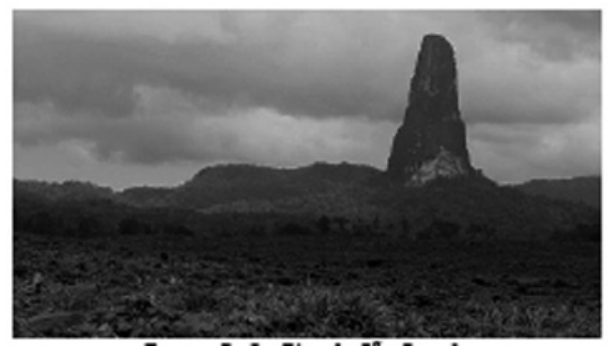

Fotografia 3: Pico do Cão Grande

Ilhéu Santana (Fotografias 7 e 8), Ilhéu Chapéu de Jóquei (Fotografia 9), entre muitos outros- e ser equacionada no sentido de potenciar um patrimonio geológico que se pode mostrar relevante à escala nacional, local ou regional, conforme refe-
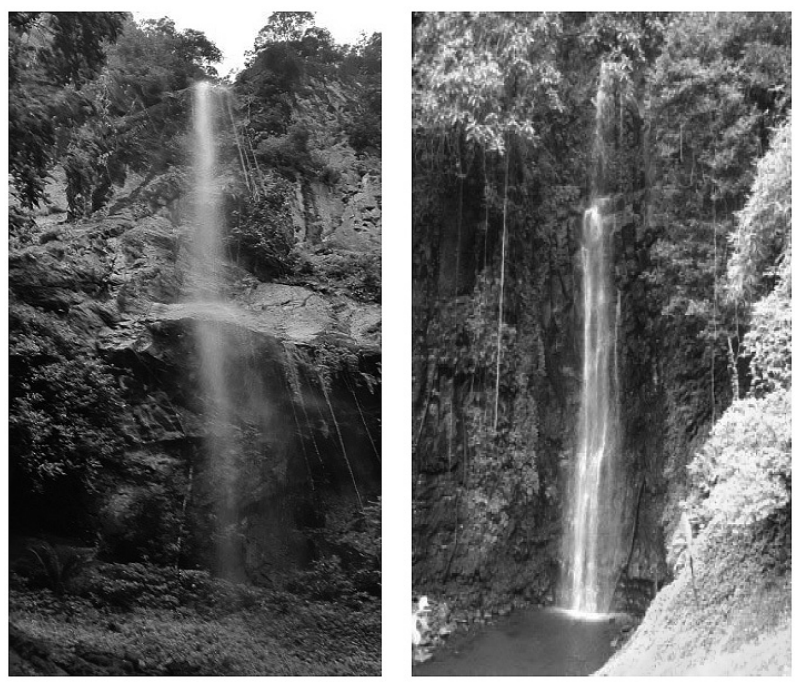

Fotografias 4 e 5: Cascatas de S. Nicolau, em São Tomé e Ôque Pipi, na Ilha do Príncipe
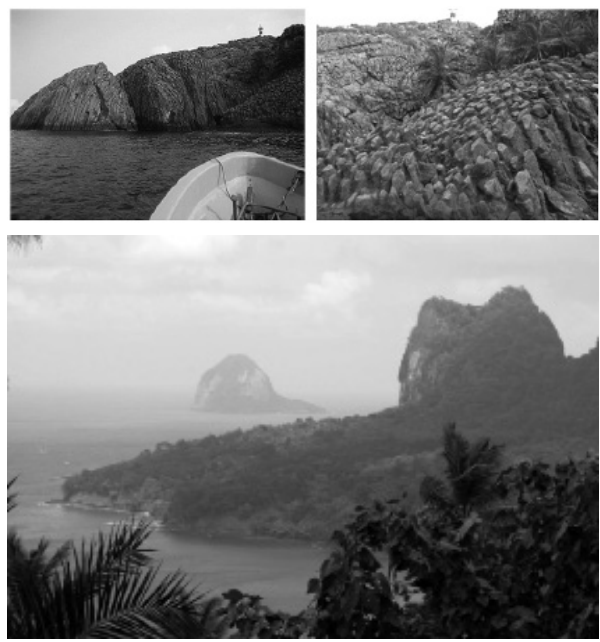

Fotografias 7 e 8: Ilhéu Santana e Pormenor da disjunção colunar ou prismática do basalto Fotografia 9: Ilhéu Chapéu de Jóquei

rem MuÑOZ (1998) e BRILHA (2005), referidos por Nascimento, Mantesso-Neto \& Ruchkys (2008).

Com efeito, através de uma concertada estraégia de conservação, uma rede de

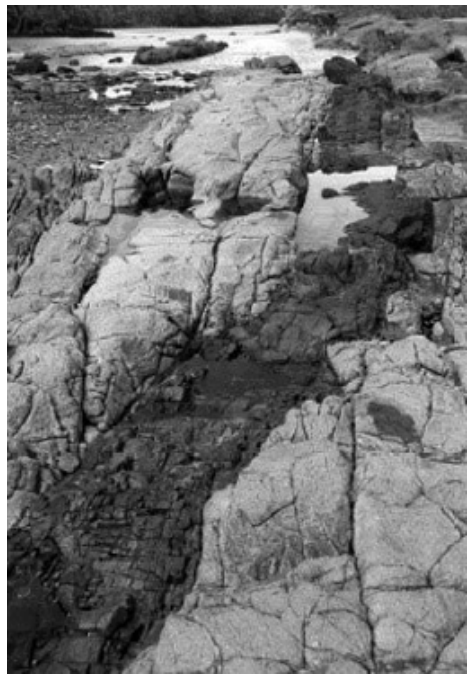

Fotografia 6: Filão no Ilhéu Bom Bom, na Ilha do Príncipe 
geossítios em São Tomé e Príncipe pode, através das suas múltiplas perspetivas de valorização - cultural, turística, cientíco-pedagógica, estética, económica, entre outras - gerar uma estraégia de geoconservação e valorização deste património, contribuindo de forma decisiva para a consolidação de um modelo de desenvolvimento mais harmonioso para o País, em pleno respeito pelo ambiente e seres vivos que o compôem.

Considerando que GonçALVES, et all (2007), citando OlIVEIRA (1987), salienta a importância da educação ambiental na resolução de problemas concretos no ambiente em que o Homem vive, e, citando Branco (1999), enfatiza que ela é responável pela modificação de mentalidades e da forma de encarar o meio e a Vida, torna-se evidente a necessidade de a promover junto das comunidades em geral, dos decisores políticos e dos gestores do territorio e seus recursos, mais em particular, de forma a salvaguardar o património natural de São Tomé e Príncipe.

Em suma, urge desenvolver uma política nacional visando a identificação, caracterização, recuperação, conservação, valorização, divulgação e correta gestão do património geológico nacional, tanto mais que o mesmo pode vir a revelar-se mais uma fonte de desenvolvimento económico para o país e para as suas comunidades. Torna-se, também, essencial integrar e articular as políticas de educação ambiental e de conservação do património geológico (e da Conservação da Natureza em geral) envolvendo sempre as populações na proteção e exploração racional e sustentada do seu património geológico, mas também biológico e paisagístico, através de iniciativas coordenadas com todos os atores com que este se relaciona.

\section{Referências bibliográficas}

BRILHA, J.; PEREIRA, P.; PEREIRA, D.; HEMNRIQUES, R. (2013). Geossítios de Relevância nacional e Internacional em Portugal Continental (pp. 169-176). In Magalhães, M. R. (Coord.) (2013). Estrutura Ecológica nacional - Uma proposta de delimitação e regulamentação. Lisboa, ISAPress

CARDOSO, J. C.; GARCIA, J.S. (1962). Carta dos solos de São Tomé e Príncipe. Lisboa: Memórias da Junta de Investigações do Ultramar, segunda série, $\mathrm{n}^{\circ} 39$.

GONÇALVES, F. (2010): Os Cetáceos em São Tomé e Príncipe: A luta pela Biodiversidade e Dignidade de um Povo (pp.122-138). in Brito, B. (Coord.) (2010). Abrindo trilhos tecendo redes - reflexões e experiências de desenvolvimento local em contexto lusófono. Lisboa, Gerpress.

GONÇALVES, F.; PEREIRA, R.; AZEITEIRO, M.M.U.; PEREIRA, M.J.V. (2007): Actividades práticas em Ciência e Educação Ambiental. Lisboa, Instituto Piaget

LEVENTIS. A.P.; OLMOS, F. (2009): As Aves de São Tomé e Príncipe: um guia fotográfico / The Birds of São Tomé e Príncipe: a photoguide (bilingue). $1^{\text {a }}$ ed. S. Paulo, Brasil, Alves \& Fotos Editora.

LIMA, R.F. (2012): Alterações do uso do solo e biodiversidade em São Tomé. in Actas do Colóquio Internacional São Tomé e Príncipe numa perspectiva interdisciplinar, diacrónica e sincrónica (pp. 455-464). Lisboa: Instituto Universitário de Lisboa (ISCTE-IUL), Centro de Estudos Africanos e Instituto de Investigação Científica Tropical (IICT), 
MARAPA (2009): Ecologia e Educação Ambiental em S. Tomé e Príncipe. S. Tomé e Príncipe: MARAPA; CTA.

MENDES, L.F.; SOUSA, A. B. (2012): Riqueza de espécies e endemicidade das borboletas diurnas (Lepidoptera: Rhopalocera) de São Tomé e Príncipe (pp. 653-663). in Actas do Colóquio Internacional São Tomé e Príncipe numa perspectiva interdisciplinar, diacrónica e sincrónica. Lisboa: Instituto Universitário de Lisboa (ISCTE-IUL), Centro de Estudos Africanos e Instituto de Investigação Científica Tropical (IICT).

MUNHÁ, J.; CALDEIRA, R.; MADEIRA, J.; MATA, J.; AFONSO, R. (2007): Geologia da ilha de S. Tomé. Notícia explicativa da carta geológica na escala 1:25000. Lisboa, Cooperação portuguesa e IPAD - Instituto Português de Apoio ao Desenvolvimento
NASCIMENTO, M.A.L.; MANTESSO-NETO, V.; RUCHKYS, U.A. (2008): Geodiversidade, geoconservação e geoturismo: trinômio importante para a proteção do patrimônio geológico. São Paulo, SBG.

OLIVEIRA, M.; SANTOS, O. (2013): Património Natural de São Tomé e Príncipe - Conhecer para Preservar. Ed. Instituto Marquês de Valle Flôr (Edição digital - http://imvf.org/ficheiros/ file/brochurapatrimonionatural.pdf)

PINTO, J.R.; LIMA, J.P. (Coord) (2014): Manual de Educação Ambiental - São Tomé e Príncipe Ecossistemas, impactes ambientais e gestão responsável dos recursos naturais. São Tomé e Príncipe, MARAPA/ASPEA 